\title{
Combined Administration of Human Ghrelin and Human Growth Hormone Attenuates Organ Injury and Improves Survival in Aged Septic Rats
}

\author{
Weng-Lang Yang, ${ }^{1,2}$ Gaifeng Ma, ${ }^{1}$ Mian Zhou, ${ }^{2}$ Monowar Aziz, ${ }^{2}$ Hao-Ting Yen, ${ }^{1}$ Spyros A Marvropoulos, ${ }^{3}$ \\ Kaie Ojamaa, ${ }^{2}$ and Ping Wang ${ }^{2}$ \\ ${ }^{1}$ TheraSource LLC, Manhasset, New York, United States of America; ${ }^{2}$ Center for Immunology and Inflammation, The Feinstein \\ Institute for Medical Research, Manhasset, New York, United States of America; and ${ }^{3}$ Hofstra Northwell School of Medicine, \\ Hempstead, New York, United States of America
}

\begin{abstract}
Sepsis is a major healthcare concern, especially in the elderly population. The use of an animal model closely resembling clinical conditions in this population may provide a better prediction in translating bench studies to the bedside. Ghrelin inhibits sympathetic nerve activity and inflammation in young septic animals; however, aged animals become hyporesponsive to ghrelin. In this study, we evaluated the efficacy of combined human ghrelin and growth hormone (GH) for sepsis treatment in the elderly utilizing a clinically relevant animal model of sepsis. Male Fischer 344 rats 22 to 24 months old were subjected to cecal ligation and puncture (CLP). Human ghrelin plus $\mathrm{GH}$ or vehicle (normal saline) was administered subcutaneously at $5 \mathrm{~h}$ after CLP. At $20 \mathrm{~h}$ after CLP, blood and tissue samples were collected for various analyses. Combined treatment attenuated serum levels of lactate, lactate dehydrogenase, creatinine, blood urea nitrogen, interleukin-6 (IL-6) and tumor necrosis factor- $\alpha$ (TNF- $\alpha$ ) in aged septic rats. The integrity of the microscopic structure in the lungs, liver and kidneys was well preserved after treatment. Expression of IL-6, TNF- $\alpha$, macrophage inflammatory protein-2 and keratinocyte-derived chemokine as well as myeloperoxidase activity and caspase-3 activation were significantly reduced in the lungs and liver of treated rats. Moreover, treated rats showed an improvement in cardiovascular function and increased expression of ghrelin receptor and c-fos in the brainstem. Finally, the 10-d survival of aged septic rats was increased from $29 \%$ to $64 \%$ after combined treatment and was associated with less body weight loss. Our findings warrant the development of combined human ghrelin and $\mathrm{GH}$ for sepsis treatment in the geriatric population.
\end{abstract}

Online address: http://www.molmed.org

doi: $10.2119 / \mathrm{molmed} .2015 .00255$

\section{INTRODUCTION}

Sepsis is the body's overwhelming immune response to infection, which can lead to multiple organ failure and often death $(1,2)$. In the United States, approximately 750,000 cases of sepsis occur each year, of which at least 225,000 are fatal $(1,3)$. Despite numerous studies aimed at advancing the understanding of the pathophysiology of sepsis and developing therapeutic

Address correspondence to Ping Wang, The Feinstein Institute for Medical Research, 350 Community Drive, Manhasset, NY 11030. Phone: 516-562-341 1; Fax: 516-562-1022; E-mail: pwang@northwell.edu.

Submitted December 10, 2015; Accepted for publication January 21, 2016; Published Online (www.molmed.org) January 25, 2016.

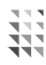

辣

Feinstein Institute for Medical Research Northwell Health" candidates for clinical trials, currently no effective pharmacotherapy exists for the treatment of sepsis. Most studies in the sepsis literature use young adult animals as a model to study host response. However, the prevalence and severity of sepsis increase with age. The overall incidence of sepsis increases from less than $0.05 \%$ in the 20 - to 29 -year-old age bracket to 1.0 to $1.5 \%$ in patients aged 70 to 79 years, and up to $2.6 \%$ in 
gland, it is also ubiquitously expressed, indicating pleiotropic effects $(9,10)$. Ghrelin not only regulates pituitary hormone secretion, food intake and energy homeostasis, but it also maintains the physiological activities of the gastrointestinal, cardiovascular and immune systems $(11,12)$. Furthermore, we and others have demonstrated that administration of ghrelin can inhibit inflammatory responses, attenuate organ injury, maintain cardiovascular stability and reduce mortality in young septic animals (13-18). The activation of the vagus nerve through GHSR-1a in the brainstem that contains parasympathostimulatory nuclei is a primary mechanism for ghrelin's beneficial effect in sepsis (14).

When given to aged animals with endotoxin-induced sepsis, rat ghrelin's activity in attenuating proinflammatory cytokine production and organ injury is diminished (19). In contrast to young animals, significantly lower levels of GHSR-1a in the brain and lower levels of serum GH are found in aged animals (19). These two factors result in the hyporesponsiveness to ghrelin treatment observed in aged septic animals (19). We have further demonstrated that coadministration of rat $\mathrm{GH}$, which functions as a ghrelin sensitizing agent, with rat ghrelin restores its beneficial effect of attenuating sepsis severity in aged animals (19). Like rats, GH levels in humans decline at a rate of approximately $15 \%$ per decade after age 25 , which is associated with many symptoms of aging including wrinkles, gray hair, hair loss, cardiovascular disease and osteoporosis $(20,21)$. GH is a strong anabolic hormone that enhances protein synthesis, promoting tissue recovery and improving host defenses (22-24).

Based on our discovery of the synergic effect of combined treatment with rat ghrelin and rat $\mathrm{GH}$, in this study we further evaluated the potential of coadministering human ghrelin and human $\mathrm{GH}$ as a treatment for sepsis in the elderly population. Although rat and human ghrelins differ in only two amino acid residues (5), rat GH shares only approximately $65 \%$ homology with human GH in its protein sequence. We used cecal ligation and puncture (CLP), a more clinically relevant model than endotoxemia (25), to induce polymicrobial sepsis in aged rats (22 to 24 months old). We then examined the effect of the combined treatment on organ injury in the lungs, liver and kidneys, as well as proinflammatory cytokine and chemokine production. We also analyzed cardiac performance and measured neutrophil infiltration and apoptosis in the organs of aged septic rats after combined treatment. In addition, we determined the effect of the combined treatment on the expression of GHSR-1a and neuronal activation in the brainstem. Finally, we conducted a 10-d survival study to evaluate the overall efficacy of the combined treatment on rescuing aged septic rats.

\section{MATERIALS AND METHODS}

\section{Experimental Animals}

Male, 22- to 24-month-old Fischer rats obtained from Charles River Laboratories via the National Institute on Aging, National Institutes of Health (NIH), were housed in a temperature controlled room under a $12 \mathrm{~h}$ light-dark cycle and fed a standard Purina rat chow diet. Rats were fasted for $6 \mathrm{~h}$ before the procedure. All experiments were performed in accordance with the NIH guidelines for use of experimental animals (Guide for the Care and Use of Laboratory Animals, 8th edition, 2011), and this study was approved by the Institutional Animal Care and Use Committee of the Feinstein Institute for Medical Research.

\section{Rat Model of Sepsis}

Sepsis in aged rats was induced by CLP as described previously (15). Briefly, rats were anesthetized by isoflurane inhalation, and a 2-cm ventral midline laparotomy was performed. The cecum was then exposed, ligated using 4-0 silk suture just distal to the ileocecal valve, punctured twice with an 18-G needle, and returned to the abdominal cavity. The abdominal incision was closed in layers using 4-0 silk suture, and the animals were resuscitated with $30 \mathrm{~mL} /$ $\mathrm{kg}$ body weight (BW) normal saline subcutaneously immediately after surgery. Sham-operated rats which served as control underwent the same surgical procedure except that the cecum was neither ligated nor punctured.

\section{Administration of Human Ghrelin and Human Growth Hormone}

Human ghrelin (Phoenix Pharmaceuticals) and human GH (ProSpec) were dissolved in normal saline. Cocktails of human ghrelin and GH were prepared by combining them at two different concentrations, which were named GG-1 (40 nmol/kg human ghrelin and $25 \mu \mathrm{g} / \mathrm{kg}$ human GH) and GG-2 (80 nmol/ kg human ghrelin and $50 \mu \mathrm{g} / \mathrm{kg}$ human $\mathrm{GH})$. At $5 \mathrm{~h}$ after CLP, rats were injected subcutaneously with a single bolus dose of GG-1, GG-2 or vehicle (normal saline) in a volume of $500 \mu \mathrm{L}$.

\section{Measurements of Serum Organ Injury Markers and Proinflammatory Cytokines}

Blood samples were collected at $20 \mathrm{~h}$ after CLP. Serum levels of lactate, lactate dehydrogenase (LDH), creatinine and blood urea nitrogen (BUN) were determined by using commercially available assay kits following the manufacturer's instructions (Pointe Scientific). The concentrations of interleukin-6 (IL-6) and tumor necrosis factor- $\alpha$ (TNF- $\alpha$ ) were quantified using enzyme-linked immunosorbent assay (ELISA) kits (BioSource International).

\section{Histological Analysis}

Lung, liver and kidney tissues were excised and fixed in 10\% formalin and then embedded in paraffin. Tissues were sectioned at a thickness of $5 \mu \mathrm{m}$ and stained with hematoxylin and eosin (H\&E). All tissue sections were evaluated under light microscopy independently by two investigators in 
a blinded manner. Severity of lung injury was scored 0 to 4 based on the presence of edema, interstitial congestion, neutrophilic infiltrates and cellular hyperplasia (15). The scoring was: 0 , none; 1 , less than $25 \% ; 2,25 \%$ to $50 \% ; 3,51 \%$ to $75 \%$; and 4 , more than $75 \%$. Severity of liver and kidney injury were scored 0 (absent), 1 (a few), 2 (mild), 3 (moderate), to 4 (severe) for each of the parameters. The parameters for liver injury are hepatocytes vacuolization, nuclear fragmentation and cell necrosis (26). The parameters for kidney injury are tissue necrosis, loss of brush border in tubular epithelial cells and formation of tubular cast (27). The histology injury scores for liver and kidney were expressed as the sum of the individual scores. Ten high-power fields per sample were scored and averaged to represent each animal.

\section{Reverse Transcription-Polymerase Chain Reaction (qPCR) Analysis}

RNA was extracted from lung and liver tissues using TRIzol Reagent (Invitrogen). Three $\mu \mathrm{g}$ of total RNA was reverse transcribed to cDNA using murine leukemia virus reverse transcriptase (Applied Biosystems). The qPCR reaction was performed in $20 \mu \mathrm{L}$ of final volume containing $0.08 \mu \mathrm{mol}$ of forward and reverse primer, $1 \mu \mathrm{L}$ cDNA and $10 \mu \mathrm{L}$ SYBR Green PCR Master Mix (Applied Biosystems). The thermal conditions include $50^{\circ} \mathrm{C}$ for $2 \mathrm{~min}, 95^{\circ} \mathrm{C}$ for $10 \mathrm{~min}, 45$ cycles of $95^{\circ} \mathrm{C}$ for $15 \mathrm{~s}$, and $60^{\circ} \mathrm{C}$ for $1 \mathrm{~min}$. Rat $\beta$-actin primer was used for normalization of expression of the gene of interest. Relative expression of mRNA was represented as fold change in comparison to the sham group. The following rat mRNA specific primer sets were used: macrophage inflammatory protein-2 (MIP-2; NM_053647.1), forward: 5'-CGCCC AGACA GAAGT CATAG-3', reverse: 5'-CCTTT CCAGG TCAGT TAGCC-3'; keratinocyte derived chemokine (KC; NM_030845.1), forward: 5'-GGCAG GGATT CACTT CAAGA-3', reverse:
5'- GCCAT CGGTG CAATC TATCT-3'; and $\beta$-actin (NM_031144.3), forward: 5'-CGTGA AAAGA TGACC CAGAT CA-3'; reverse: 5'-TGGTA CGACC AGAGG CATAC AG-3'.

\section{Measurement of Myeloperoxidase (MPO) Activity}

Lung and liver tissues were homogenized in $\mathrm{KPO}_{4}$ buffer containing 0.5\% hexa-decyl-trimethyl-ammonium bromide by sonication. The samples were centrifuged, and the supernatants were diluted in the reaction solution containing $o$-dianisidine hydrochloride and $\mathrm{H}_{2} \mathrm{O}_{2}$ in phosphate buffer in a 96-well plate. The rate of change in absorbance per min was measured at $460 \mathrm{~nm}$ to calculate MPO activity units per gram of protein in tissue samples.

\section{Western Blot Analysis}

The tissue samples were homogenized in lysis buffer $(10 \mathrm{mmol} / \mathrm{L}$ Tris- $\mathrm{HCl} \mathrm{pH}$ 7.5, $120 \mathrm{mmol} / \mathrm{L} \mathrm{NaCl}, 1 \% \mathrm{NP}-40,1 \%$ sodium deoxycholate and $0.1 \%$ sodium dodecyl sulfate) containing protease inhibitor cocktail (Roche Diagnostics), then sonicated. Protein concentrations were determined by Bio-Rad protein assay reagent. Fifty $\mu \mathrm{g}$ of total protein lysate was electrophoresed on NuPAGE 4 to $12 \%$ Bis-Tris Gel (Invitrogen) and transferred to nitrocellulose membranes. The membranes were then blocked with $0.1 \%$ casein in phosphate-buffered saline and then incubated with anti-cleaved caspase-3 (Cell Signaling), anti-GHSR-1a (EMD Millipore), c-fos (Sigma-Aldrich) and $\beta$-actin (Sigma-Aldrich). After washing, the membranes were incubated with fluorescently-labeled respective secondary antibodies (LI-COR). The Odyssey image system (LI-COR) was then used to scan the membranes, followed by measurement of the band intensities using Odyssey densitometric software.

\section{Measurement of Cardiac Contractile Function In Vivo}

Twenty hours after sham or CLP operation, rats were anesthetized with sodium pentobarbital (35 mg/kg BW) via intraperitoneal injection. Core body temperature was monitored and maintained at $37^{\circ} \mathrm{C}$. A midventral incision was made on the neck, and the right carotid artery was separated and cannulated using a PE-25 catheter. A 1F Millar pressure catheter was inserted into the carotid artery and advanced into the left ventricle (LV). After a period of stabilization, LV functional parameters, including the LV developing pressure (LVDP), maximum rate of ventricular pressure development $\left(+\mathrm{dP} / \mathrm{dt}_{\text {max }}\right.$, $\mathrm{mmHg} / \mathrm{s}$ ) and heart rate were recorded using PowerLab and analyzed with LabChart (AD Instruments). Cardiac work product was calculated by multiplying LVDP by heart rate.

\section{Survival Study}

Aged rats were subjected to CLP as described previously and received a subcutaneous injection of GG-2 (80 nmol/kg human ghrelin and $50 \mu \mathrm{g} / \mathrm{kg}$ human $\mathrm{GH}$ ) or vehicle (normal saline) at $5 \mathrm{~h}$ after CLP. Immediately following CLP, rats were resuscitated using subcutaneous saline and antibiotics (imipenem and cilastatin, $0.5 \mathrm{mg} / \mathrm{kg} \mathrm{BW}$ ). The animals were then allowed food and water ad libitum and were monitored for $10 \mathrm{~d}$ to record survival and BW changes.

\section{Statistical Analysis}

All data were expressed as the mean \pm standard error (SE) and compared by one-way analysis of variance and Student-Newman-Keuls method for multiple-group comparisons. Survival rate was determined by the Kaplan-Meier estimator and compared by a log-rank test. Differences in values were considered significant if $P<0.05$.

\section{RESULTS}

\section{Coadministration of Human Ghrelin and GH Attenuates Organ Injury and Systemic Inflammation in Aged Septic Rats}

We first measured serum levels of several organ injury markers at $20 \mathrm{~h}$ after CLP. Lactate levels are commonly 
evaluated in acutely ill patients, especially in patients with shock (28). Sepsis in aged rats significantly induced serum levels of lactate, whereas combined treatment with human ghrelin and GH in aged septic rats significantly reduced the serum lactate levels by $43.1 \%$ and $39.8 \%$ at doses of $40 \mathrm{nmol}-25 \mu \mathrm{g} / \mathrm{kg}$ (GG-1) and $80 \mathrm{nmol}-50 \mu \mathrm{g} / \mathrm{kg}$ (GG-2),

A

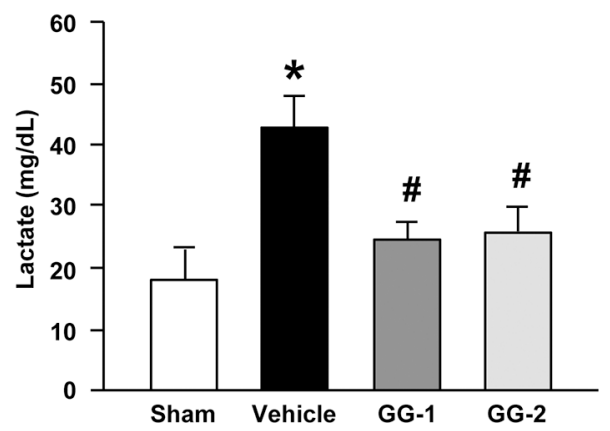

C

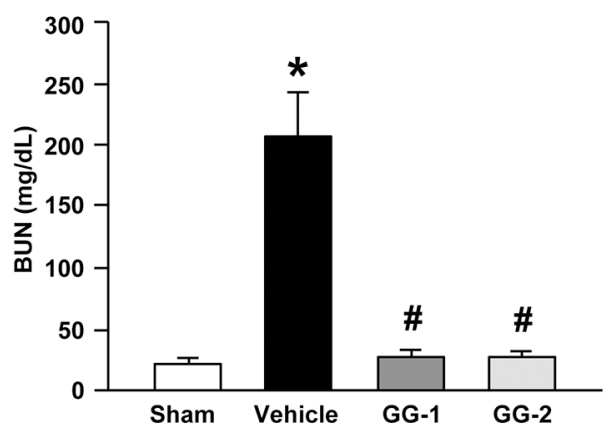

E

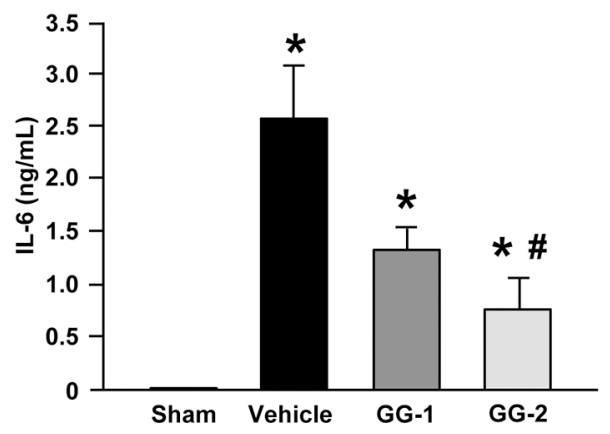

respectively, compared with the vehicle group (Figure 1A). The release of LDH into the circulation is another indicator of broad organ injury. There were $49.3 \%$ and $47.5 \%$ reductions in serum $\mathrm{LDH}$ levels in aged septic rats with GG-1 and GG-2 treatments, respectively, compared with the vehicle group (Figure 1B). Furthermore, serum levels of BUN and

\section{B}

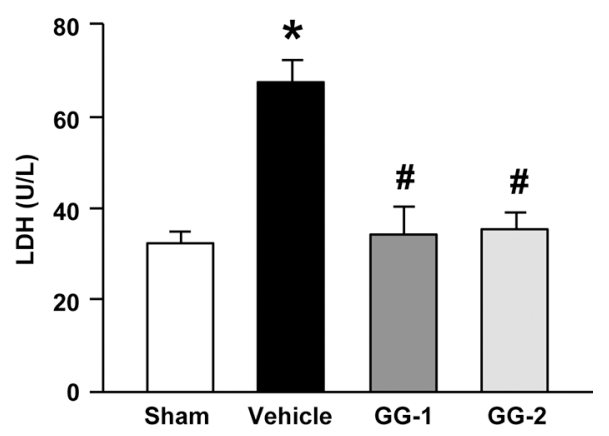

D

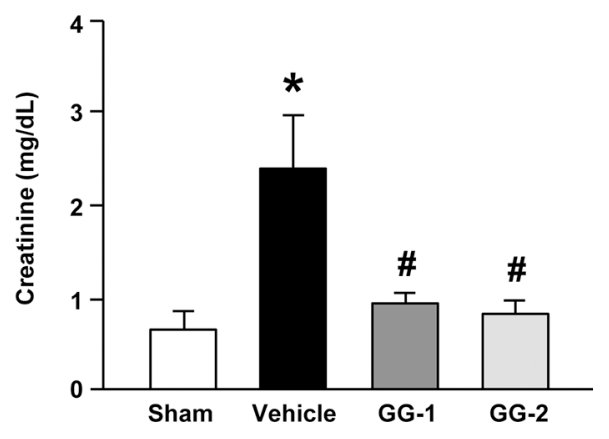

$\mathbf{F}$

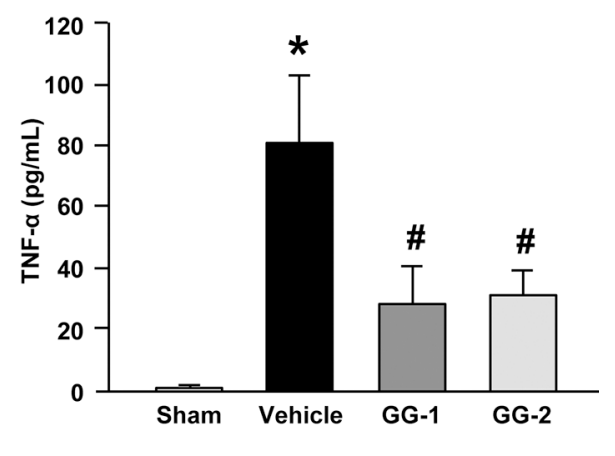

Figure 1. Effect of the combined treatment on organ injury makers and systemic inflammation in aged septic rats. Rats were sham operated or subjected to CLP with injection of vehicle (normal saline) or human ghrelin plus GH at two different doses, GG-1 (40 $\mathrm{nmol} / \mathrm{kg}$ of ghrelin and $25 \mu \mathrm{g} / \mathrm{kg} \mathrm{GH})$ and GG-2 $(80 \mathrm{nmol} / \mathrm{kg}$ of ghrelin and $50 \mu \mathrm{g} / \mathrm{kg}$ of $\mathrm{GH})$ at $5 \mathrm{~h}$ after CLP. Blood samples were collected at $20 \mathrm{~h}$ after CLP for measuring (A) lactate, (B) LDH, (C) BUN, (D) creatinine, (E) IL-6 and (F) TNF- $\alpha$. Data are expressed as mean \pm SE ( $n=5-7$ per group). ${ }^{*} P<0.05$ versus sham and ${ }^{\#} P<0.05$ versus vehicle.

creatinine, markers of renal injury, were also significantly elevated in the vehicle group, while treatment with GG-1 and GG-2 significantly decreased BUN levels by $86.2 \%$ and $86.5 \%$, respectively, as well as creatinine levels by $63.1 \%$ and $63.5 \%$, respectively (Figures $1 C, D$ ). We also measured serum levels of proinflammatory cytokines IL-6 and TNF- $\alpha$, which showed a significant increase in aged septic rats compared with sham-operated animals (Figures 1E, F). In contrast, treatment with GG-1 and GG-2 significantly reduced serum levels of IL- 6 by $49.0 \%$ and $70.5 \%$, respectively, as well as TNF- $\alpha$ by $66.1 \%$ and $60.9 \%$, respectively, compared with vehicle group (Figures 1E, F).

\section{Combined Human Ghrelin and $\mathrm{GH}$ Protects the Lungs from Damage and Inflammation in Aged Septic Rats}

After examining the effect of combined treatment at the systemic level, we then evaluated its effect in more detail at the level of individual organs. Since the effects of GG-1 and GG-2 on systemic organ injury markers and inflammation were comparable, we focused our attention on GG-2 treatment in subsequent data analyses. Acute lung injury can develop both in response to a direct insult to the lung and indirectly due to the systemic inflammatory response caused by sepsis (29). At $20 \mathrm{~h}$ after CLP, the lung histopathology in vehicle-treated rats showed considerable edema, hemorrhage, alveolar collapse and inflammatory cell infiltration, compared with sham (Figure 2A). In contrast, GG-2 treatment markedly reduced microscopic deterioration in the lungs compared with vehicle-treated rats (Figure $2 \mathrm{~A}$ ). As quantified in Figure 2B, the lung histological injury score in the GG-2 treatment group exhibited a significant reduction by $46.2 \%$ in comparison to that in the vehicle group.

We next examined the inflammatory response in the lungs at $20 \mathrm{~h}$ after CLP. Aged septic rats treated with GG-2 showed a significant, $29.9 \%$, reduction in levels of proinflammatory cytokine 
A

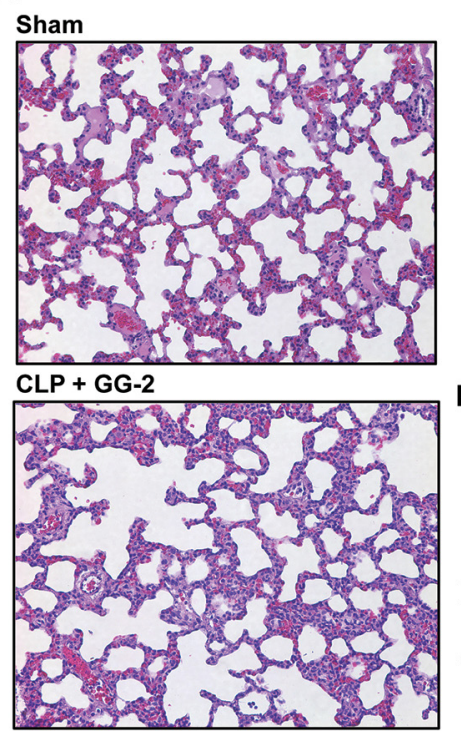

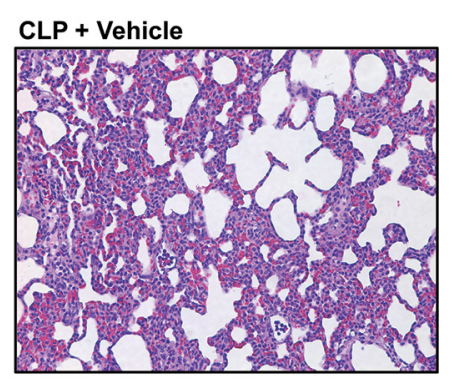

B

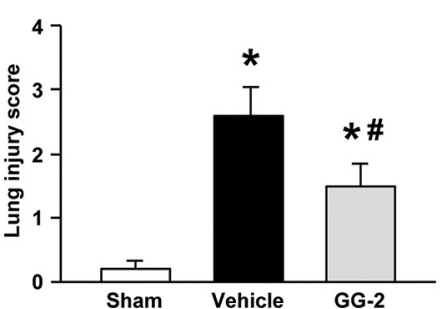

Figure 2. Effect of the combined treatment on the morphological structure of lung tissues in aged septic rats. Rats were sham operated or subjected to CLP with injection of vehicle (normal saline) or GG-2 ( $80 \mathrm{nmol} / \mathrm{kg}$ of ghrelin and $50 \mu \mathrm{g} / \mathrm{kg}$ of $\mathrm{GH}$ ) at $5 \mathrm{~h}$ after CLP. The lung tissues were harvested at $20 \mathrm{~h}$ after CLP. Sections of lung tissues were stained with H\&E and examined under light microscopy. (A) Representative images of the stained lung tissues are shown. Original magnification 200x. (B) Histologic injury scores of the lungs in different groups were quantified as described in Materials and Methods. Data are expressed as mean $\pm \mathrm{SE}$ ( $n=5-7$ per group). ${ }^{*} P<0.05$ versus sham and ${ }^{\#} P<0.05$ versus vehicle.

A

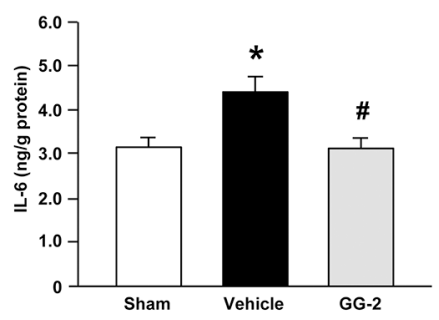

C

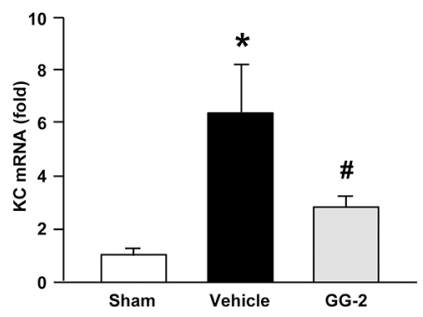

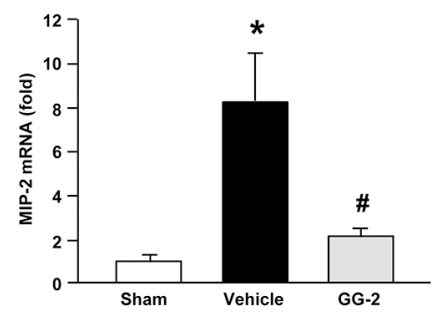

D

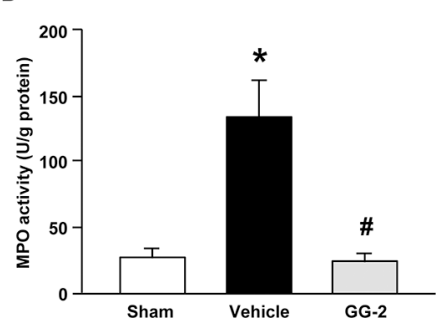

Figure 3. Effect of the combined treatment on lung inflammation in aged septic rats. Rats were sham operated or subjected to CLP with injection of vehicle (normal saline) or GG-2 ( $80 \mathrm{nmol} / \mathrm{kg}$ of ghrelin and $50 \mu \mathrm{g} / \mathrm{kg}$ of $\mathrm{GH}$ ) at $5 \mathrm{~h}$ after CLP. The lung tissues were harvested at $20 \mathrm{~h}$ after CLP for measuring (A) protein levels of IL-6 by ELISA, mRNA levels of (B) MIP-2 and (C) KC by QPCR, and (D) MPO activity by colorimetric assay. mRNA levels in sham group are designated 1 for comparison. Data are expressed as mean \pm SE ( $n=5-7$ per group). ${ }^{*} P<0.05$ versus sham and ${ }^{*} P<0.05$ versus vehicle.

IL-6 compared with the vehicle group (Figure 3A). In addition, mRNA levels of proinflammatory chemokines MIP-2 and $\mathrm{KC}$ in the lungs were elevated in aged septic rats, while they were significantly decreased by $74.7 \%$ and $56.5 \%$, respectively, after treatment with GG-2 (Figures 3B, C). It is well established that chemokines promote sequestration of neutrophils to organs, causing the release of histotoxic mediators and tissue damage (29). MPO activity, a neutrophil marker, was significantly decreased by $80.9 \%$ in the lungs of GG-2-treated aged septic rats compared with the vehicle group (Figure 3D), consistent with the above findings.

\section{Combined Human Ghrelin and GH Protects the Liver from Damage and Inflammation in Aged Septic Rats}

Sepsis often leads to multiple organ dysfunction, and the liver is frequently affected (30). As determined by H\&E staining, the microscopic architecture of liver tissue in the vehicle group was severely deteriorated. Hepatocytes vacuolization, cell necrosis and inflammatory cell infiltration were observed in the vehicle group, while the integrity of the liver architecture was largely maintained after treatment with GG-2 (Figure 4A). Semiquantitative evaluation using liver injury score showed a significant, $59.0 \%$, reduction in the GG-2 treatment group compared with vehicle group (Figure 4B). At $20 \mathrm{~h}$ after CLP, the protein levels of proinflammatory cytokine TNF- $\alpha$ in the liver were significantly induced in aged rats, while its levels were decreased by $49.4 \%$ after treatment with GG-2 (Figure 5A). Similarly, mRNA levels of MIP-2 and KC were also found to be significantly induced in vehicle-treated rats (Figures 5B, C). Conversely, mRNA levels of MIP-2 and $\mathrm{KC}$ in the rats that received GG-2 treatment were downregulated by $81.6 \%$ and $63.2 \%$, respectively, compared with vehicle group (Figures 5B, C). MPO activity in the liver of aged septic rats was also reduced by $53.6 \%$ after GG-2 treatment (Figure 5D). 
A

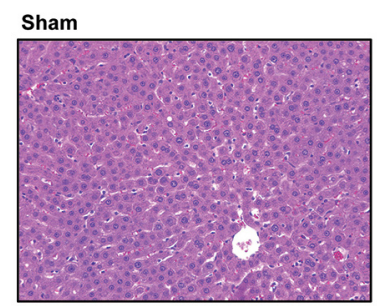

CLP + GG-2

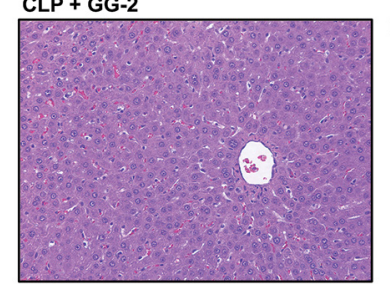

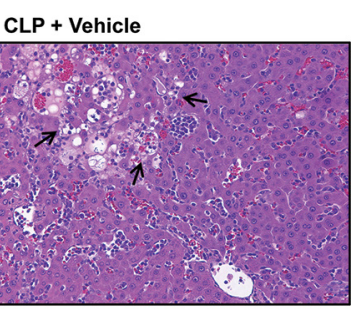

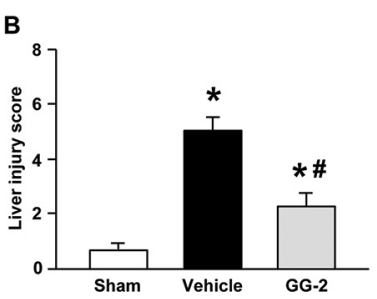

Figure 4. Effect of the combined treatment on the morphological structure of liver tissues in aged septic rats. Rats were sham operated or subjected to CLP with injection of vehicle (normal saline) or GG-2 (80 nmol/kg of ghrelin and $50 \mu \mathrm{g} / \mathrm{kg}$ of $\mathrm{GH}$ ) at $5 \mathrm{~h}$ after CLP. The liver tissues were harvested at $20 \mathrm{~h}$ after CLP. Sections of liver tissues were stained with H\&E and examined under light microscopy. (A) Representative images of the stained liver tissues are shown. Sham tissues have normal architecture, whereas the vehicle group shows hepatocytes vacuolization, cell necrosis and inflammatory cell infiltration (arrows). The treatment of GG-2 markedly maintains the integrity of the liver structure. Original magnification 200x. (B) Histologic injury scores of the liver in different groups were quantified as described in Materials and Methods. Data are expressed as mean $\pm \mathrm{SE}$ ( $n=5-7$ per group). ${ }^{*} P<0.05$ versus sham and ${ }^{\#} P<0.05$ versus vehicle.

A

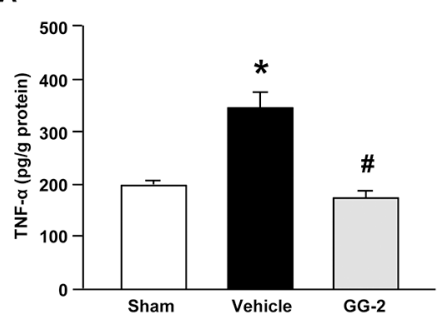

C

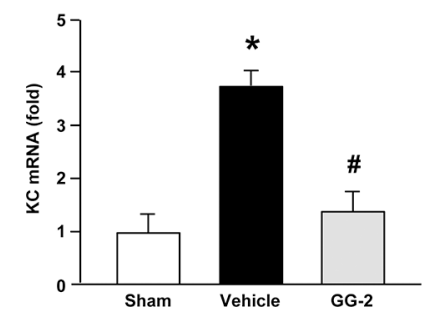

B

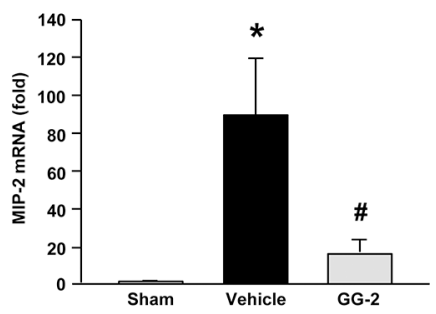

D

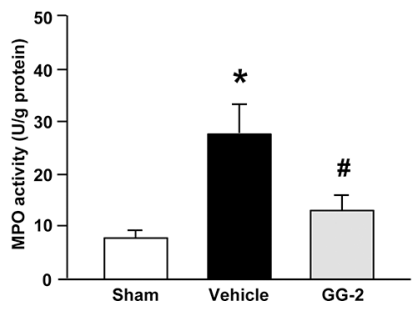

Figure 5. Effect of the combined treatment on liver inflammation in aged septic rats. Rats were sham operated or subjected to CLP with injection of vehicle (normal saline) or GG-2 (80 nmol/kg of ghrelin and $50 \mu \mathrm{g} / \mathrm{kg}$ of $\mathrm{GH})$ at $5 \mathrm{~h}$ after CLP. The liver tissues were harvested at $20 \mathrm{~h}$ after CLP for measuring (A) protein levels of TNF- $\alpha$ by ELISA, mRNA levels of (B) MIP-2 and (C) KC by qPCR, and (D) MPO activity by colorimetric assay. mRNA levels in sham group are designated 1 for comparison. Data are expressed as mean $\pm \mathrm{SE}$ ( $n=5-7$ per group). ${ }^{*} P<0.05$ versus sham and ${ }^{*} P<0.05$ versus vehicle.

\section{Combined Human Ghrelin and $\mathrm{GH}$ Protects the Kidneys from Damage in Aged Septic Rats}

Sepsis-induced acute kidney injury is another common form of organ damage observed in critically ill patients (31). Histologic evaluation of the kidneys from the vehicle group revealed tubular cell injury, loss of tubular epithelial brush border, cellular necrosis and cast formation (Figure 6A). In contrast, the extent of injury was significantly reduced in the GG-2 treatment group by $39.2 \%$ compared with vehicle-treated animals (Figure 6B).

\section{Combined Human Ghrelin and $\mathrm{GH}$ Inhibits Apoptosis in the Organs of Aged Septic Rats}

Induction of apoptosis is another major factor contributing to tissue damage in sepsis (32). We determined the status of apoptosis in the organs by measuring the activation of caspase-3, which plays a central role in executing the apoptotic cascade (32). At $20 \mathrm{~h}$ after CLP, cleaved caspase- 3 was well detected in the lung and liver tissues of vehicle-treated rats, while it was barely detectable in the sham group (Figures 7A, B). With GG-2 treatment, cleaved caspase-3 levels in the lung and liver tissues were decreased by $92.2 \%$ and $87.9 \%$, respectively, compared with vehicle group (Figures 7A, B).

\section{Combined Human Ghrelin and $\mathrm{GH}$ Improves Cardiovascular Function in Aged Septic Rats}

Cardiovascular dysfunction, specifically a reduction in cardiac contractility, is often observed in severe sepsis (33). LVDP and the maximal rate of ventricular pressure development $\left(+\mathrm{dP} / \mathrm{dt}_{\max }\right)$ were significantly decreased by $83.1 \%$ and $81.2 \%$, respectively, compared with sham rats. GG-2 treatment of CLP rats completely normalized these contractile parameters (Figures 8A, B). Cardiac work product as measured by LVDP multiplied by heart rate was significantly increased by GG-2 treatment of CLP animals, indicating a restoration of cardiac output in aged septic rats (Figure 8C). 
A

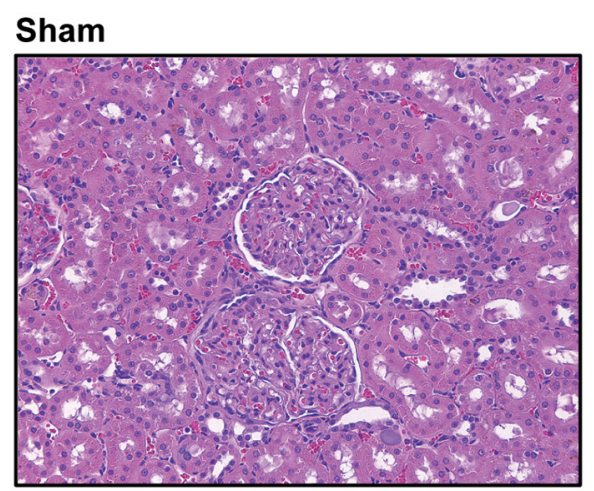

$\mathrm{CLP}+\mathrm{GG}-2$

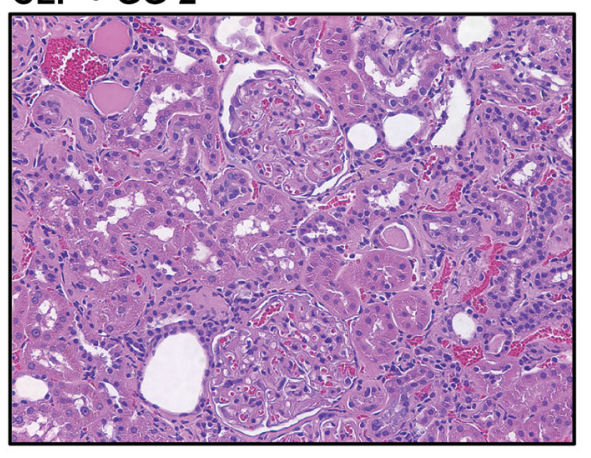

CLP + Vehicle

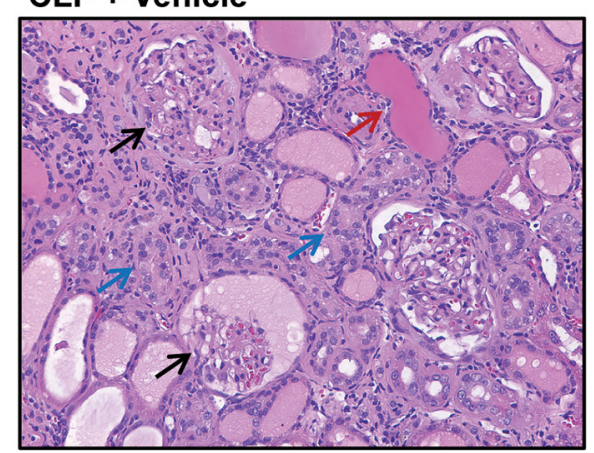

B

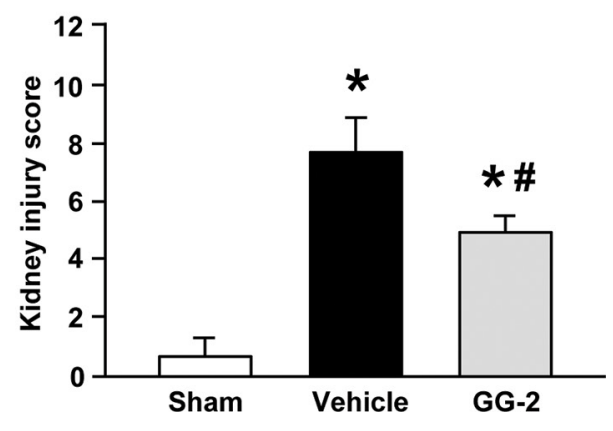

Figure 6. Effect of the combined treatment on the morphological structure of kidney tissues in aged septic rats. Rats were sham operated or subjected to CLP with injection of vehicle (normal saline) or GG-2 (80 nmol/kg of ghrelin and $50 \mu \mathrm{g} / \mathrm{kg}$ of $\mathrm{GH}$ ) at $5 \mathrm{~h}$ after CLP. The kidney tissues were harvested at $20 \mathrm{~h}$ after CLP. Sections of kidney tissues were stained with H\&E and examined under light microscopy. (A) Representative images of the stained kidney tissues are shown. The kidneys obtained from the vehicle group demonstrated a significant renal injury with glomerular destruction (black arrow), tubular proteinaceous casts (red arrow), loss of tubular brush borders and epithelial cell injury (blue arrows). The integrity of renal morphology in the GG-2 treatment group is significantly improved. Original magnification 200x. (B) Histologic injury scores of the kidney in different groups were quantified as described in Materials and Methods. Data are expressed as mean \pm SE ( $n=5-7$ per group). ${ }^{*} P<0.05$ versus sham and ${ }^{\#} P<0.05$ versus vehicle.

\section{Combined Human Ghrelin and $G H$ Activates Brain Activity in Aged Septic Rats}

It has been described that ghrelin can act through the central nervous system (14). We thus examined expression of two proteins that are known to respond to ghrelin in the brain. We first determined the effect of combined treatment on the expression of GHSR-1a. At $20 \mathrm{~h}$ after CLP, protein levels of GHSR-1a in the brainstem did not change significantly between the vehicle and sham groups (Figures 9A, B). With GG-2 treatment, the expression of GHSR-1a increased by $66.9 \%$ and $32.5 \%$ compared with vehicle and sham groups, respectively (Figures 9A, B). We also measured the protein expression of $c$-fos, a marker of neuronal activity (34). The expression levels of $c$-fos in the vehicle group were lower than those in the sham group although there was no statistical significance (Figures 9A, C). In contrast, combined treatment significantly upregulated c-fos expression by $85.8 \%$ compared with vehicle-treated rats (Figures 9A, C).

\section{Combined Human Ghrelin and $\mathrm{GH}$ Improves Survival and Prevents Body Weight Loss in Aged Septic Rats}

To evaluate the long-term efficacy of combined treatment, we conducted a 10-d survival study in aged rats after CLP. Although both GG-1 and GG-2 treatments effectively attenuated organ injury in aged septic rats, GG-2 treatment produced better reduction in serum levels of IL-6, which is considered as a prognostic marker for sepsis (35). Therefore, we selected the dosage of GG-2 for the survival study. As shown in Figure 10A, the survival rate of the vehicle group was $29 \%$, while it was significantly increased to $64 \%$ in aged septic rats with GG-2 treatment. Ghrelin also acts to stimulate food intake. We monitored the BW of these septic rats during the 10-d survival study. The average BW of vehicle-treated rats dropped precipitously to $13.9 \%$ at d 10 , while it was maintained at less than $5 \%$ BW loss in the GG-2 treatment group during the entire 10-d period (Figure 10B).

\section{DISCUSSION}

Over the past several decades, tens of thousands of patients have been enrolled in sepsis clinical trials with little success (36). Nearly $80 \%$ of septic deaths occur in patients older than 65 years (4). As the US population ages, there is an even more urgent medical need for an effective therapy to reduce sepsis-induced lethality in the geriatric population. The poor success in translating laboratory results to the clinical realm may be attributed to inadequate animal models. In this study, we have used a clinically relevant CLP model to induce polymicrobial sepsis in aged rats to evaluate the efficacy of the coadministration of human ghrelin and GH as a therapeutic candidate. We have demonstrated that this combined treatment systemically attenuates the levels of organ injury markers and inflammation in aged septic rats. We have further examined individual organs and shown a protective effect of the combined treatment on lung, liver and kidney tissue damage via 
A

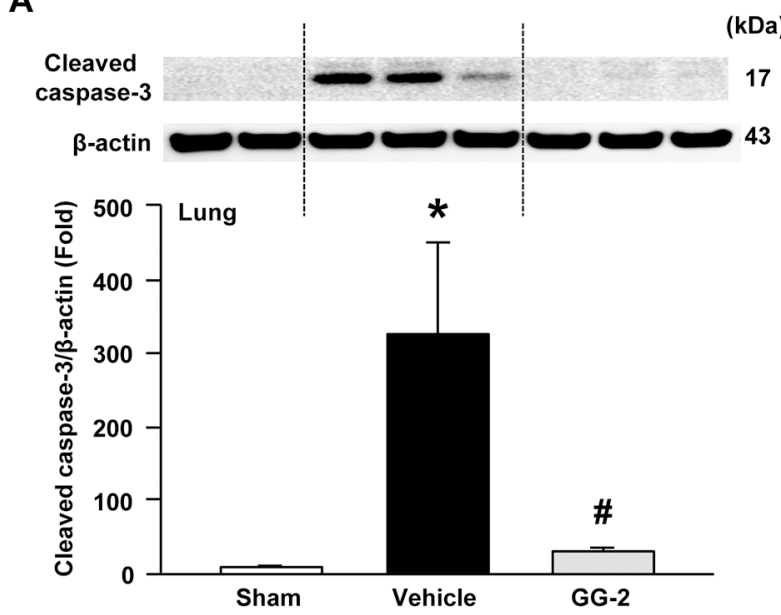

B

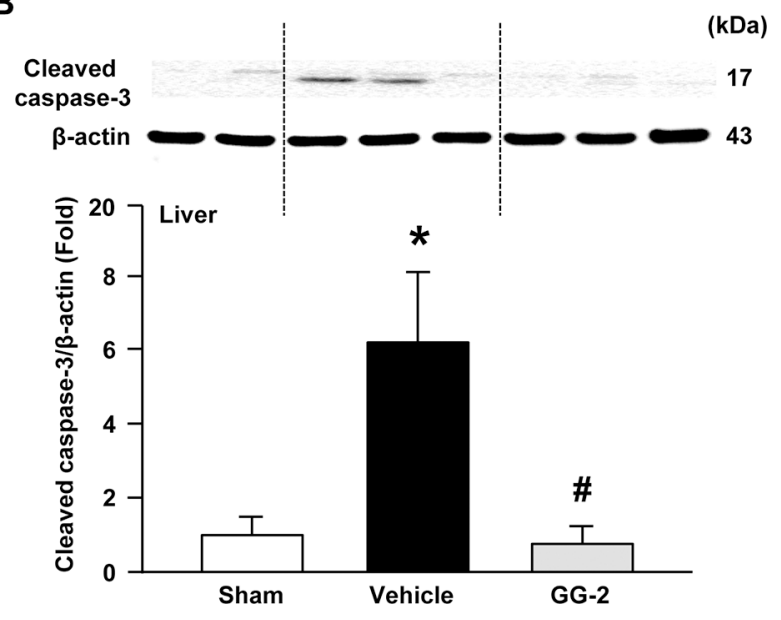

Figure 7. Effect of the combined treatment on caspase-3 activation in the organs of aged septic rats. Rats were sham operated or subjected to CLP with injection of vehicle (normal saline) or GG-2 ( $80 \mathrm{nmol} / \mathrm{kg}$ of ghrelin and $50 \mu \mathrm{g} / \mathrm{kg}$ of $\mathrm{GH}$ ) at $5 \mathrm{~h}$ after CLP. The tissues were harvested at $20 \mathrm{~h}$ after CLP for the protein extraction. Levels of cleaved caspase-3 in the (A) lung and (B) liver tissues were determined by Western blotting. Representative blots against cleaved caspase-3 and $\beta$-actin. Blots were scanned and quantified with densitometry. The levels of protein expression in sham group are designated 1 for comparison. Data are expressed as mean \pm SE ( $n=5-7$ per group). ${ }^{*} P<0.05$ versus sham and ${ }^{\#} P<0.05$ versus vehicle.

inhibition of proinflammatory cytokine and chemokine production, neutrophil infiltration and apoptosis. In addition, we have shown that the combined treatment restores the cardiovascular function in aged septic rats. Finally, we have demonstrated a significant improvement in 10-d survival rate and maintenance of BW in aged septic rats after combined treatment.

Previously, we reported the loss of sensitivity to rat ghrelin treatment in aged endotoxemic rats, which was restored by coadministering with rat GH (19). Although human GH has only $65 \%$ homology to rat $\mathrm{GH}$, in the present study, we have demonstrated that the activities both of ghrelin and of GH of human origin are similar to those of rat origin. In our previous study, we have demonstrated that protein levels of GHSR-1a in the dorsal vagal complex (DVC) of the brain stem and plasma levels of $\mathrm{GH}$ in aged rats (24 mo) are
A

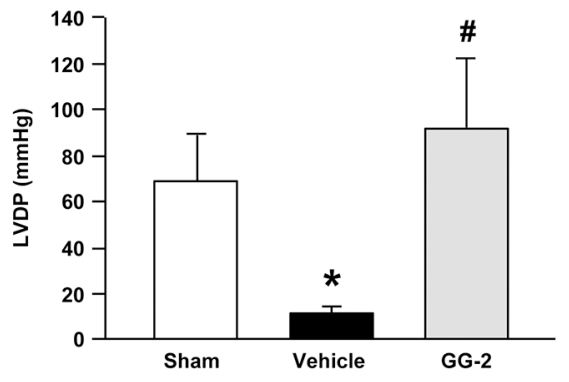

B

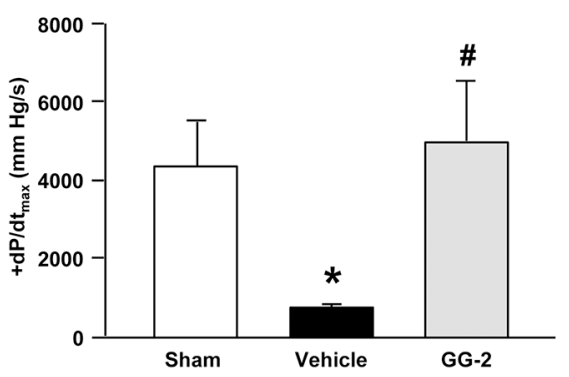

C

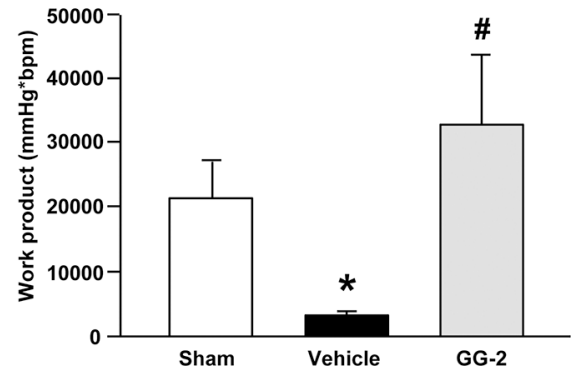

Figure 8. Effect of the combined treatment on cardiac contractile function in aged septic rats. Rats were sham operated or subjected to CLP with injection of vehicle (normal saline) or GG-2 (80 nmol/kg of ghrelin and $50 \mu \mathrm{g} / \mathrm{kg}$ of $\mathrm{GH}$ ) at $5 \mathrm{~h}$ after CLP. At 20 h after CLP, rats were anesthetized, and left ventricular pressure measurements and heart rate were recorded using a Millar pressure transducer. (A) LVDP, (B) maximal rate of ventricular pressure development $\left(+\mathrm{dP} / \mathrm{dt}_{\text {max }}\right)$ and (C) work product were calculated. Data are expressed as mean \pm SE $(n=5-7$ per group). ${ }^{*} P<0.05$ versus sham and ${ }^{\#} P<0.05$ versus vehicle.

$58 \%$ and $48 \%$ lower than those in young rats (3 months), respectively (19). We have also shown that administration of rat $\mathrm{GH}$ results in a $71 \%$ increase of 
A

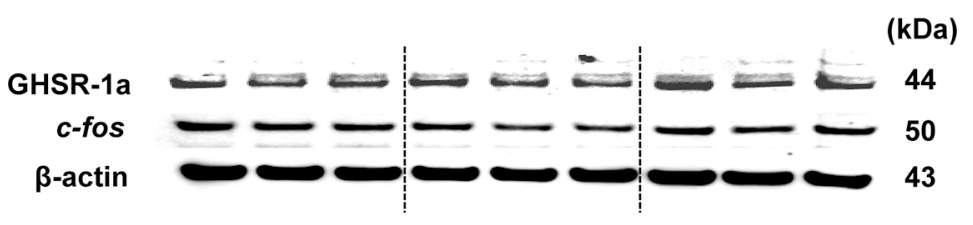

B

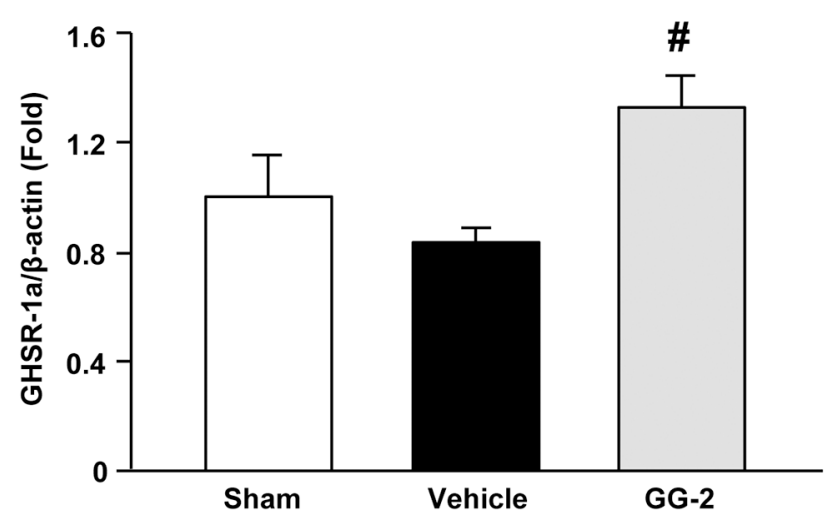

C

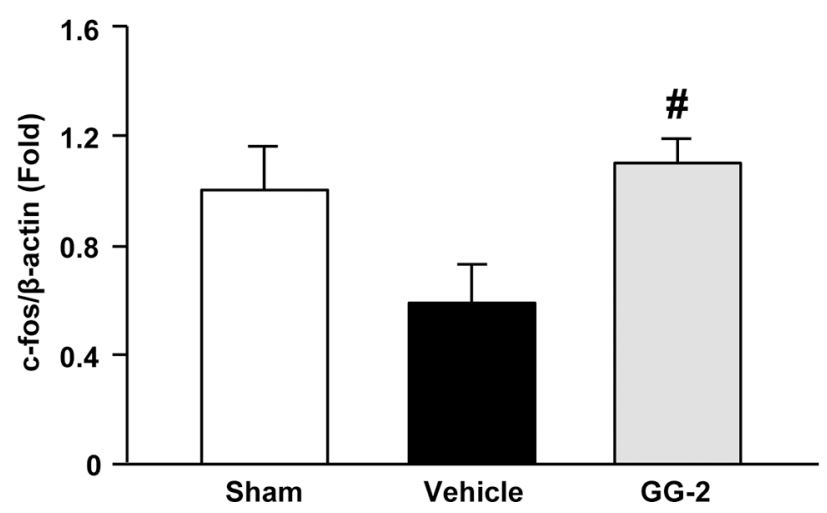

Figure 9. Effect of the combined treatment on brain activity in aged septic rats. Rats were sham operated or subjected to CLP with injection of vehicle (normal saline) or GG-2 (80 nmol/kg of ghrelin and $50 \mu \mathrm{g} / \mathrm{kg}$ of $\mathrm{GH}$ ) at $5 \mathrm{~h}$ after CLP. The brainstem was harvested at $20 \mathrm{~h}$ after CLP for protein extraction. (A) Representative Western blots against GHSR-1a, c-fos and $\beta$-actin. Quantitative levels of (B) GHSR-la and (C) c-fos in different groups. Blots were scanned and quantified with densitometry. The levels of protein expression in sham group are designated 1 for comparison. Data are expressed as mean \pm SE ( $n=5-7$ per group). ${ }^{*} P<0.05$ versus vehicle.

GHSR-1a protein expression in the DVC of aged rats (19). Like the rat proteins used in the previous study (19), here we have demonstrated that combined treatment with human ghrelin and GH can also stimulate the expression of GHSR-1a in the brainstem. With the engagement of ghrelin to its receptor GHSR-1a in the brain, it can activate the vagus nerve and in turn, through cholinergic pathways, downregulate IL- 6 and TNF- $\alpha$ release from macrophages (37). The effect of ghrelin on the central nervous system has been shown to be a main mechanism on attenuating inflammatory response in sepsis (14). When performing a vagotomy on animals subjected to CLP, we have shown that the protective effect of ghrelin administration on sepsis-induced organ injury is diminished (14).

We then have further validated the effect of the combined treatment on brain activity. It has been reported that peripheral administration of ghrelin can induce $c$-fos expression, a marker of neuronal activation, in the brain (38). In this study, we have also observed an increase of $c$-fos expression in the brainstem of aged septic rats after combined treatment. These results indicate that the combined treatment was effectively delivered to the brain. Furthermore, our previous study has demonstrated that ghrelin administration can inhibit the release of norepinephrine, a neurotransmitter, from the sympathetic nervous system in septic animals to exert its antiinflammatory effect (39). We also reported that ghrelin administration can attenuate severity of sepsis-induced acute lung injury and mortality of septic animals through inhibition of the NF- $\mathrm{B}$ pathway (15). In addition, GHSR-1a is widely distributed in the body, which provides paracrine, autocrine and endocrine roles of ghrelin in normal and pathologic conditions $(40,41)$. Taken together, in this study we have observed a broad effect of combined treatment on various organs, including lung, liver, kidney, heart and brain.

Although human ghrelin has not been approved as a prescription drug, it has been applied to 1,850 human subjects participating in more than 100 clinical studies, including healthy volunteers and patients with obesity, prior gastrectomy, cancer, pituitary disease, diabetes and eating disorders (see review in (42)). Human ghrelin has been administered via an intravenous infusion, a bolus or subcutaneous routes. Overall, these clinical studies demonstrated that human ghrelin has an excellent clinical safety profile, including in subjects with significant medical comorbidities. The most common adverse event was transitory flushing, which occurred in $10 \%$ of volunteers and resulted in discontinuation of the study medication in only 3 of the 939 participants in whom adverse event collections 
A

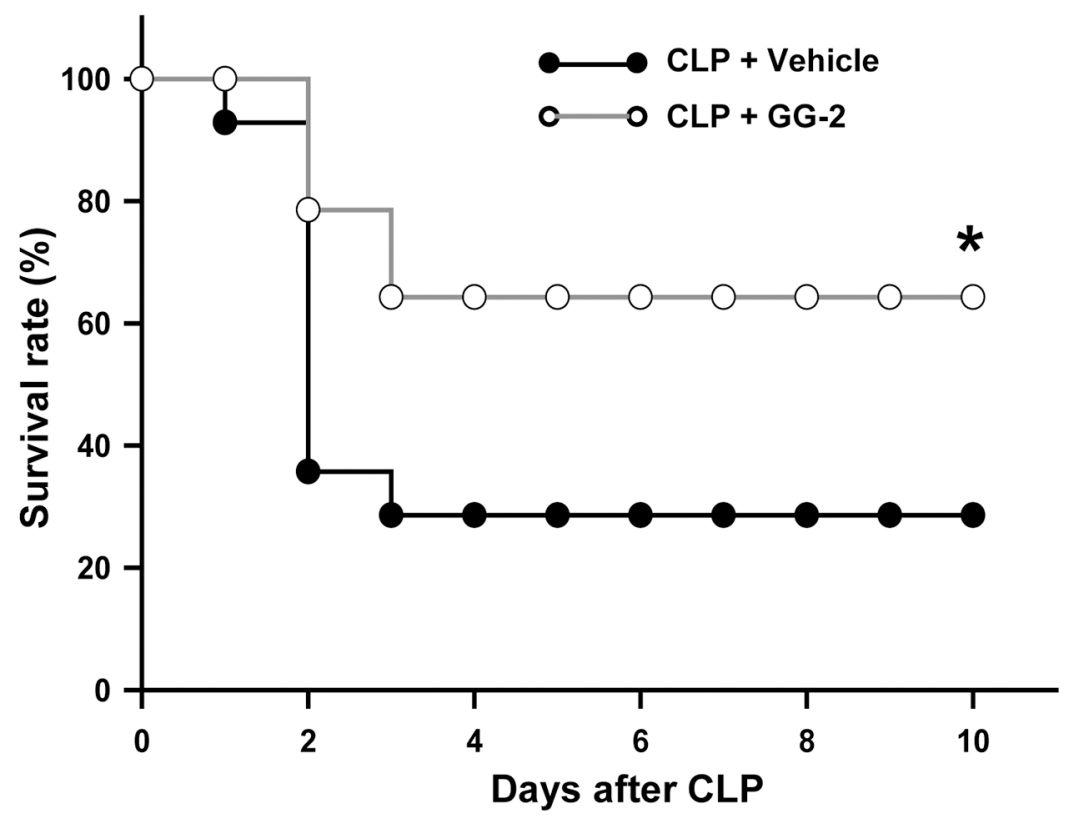

B

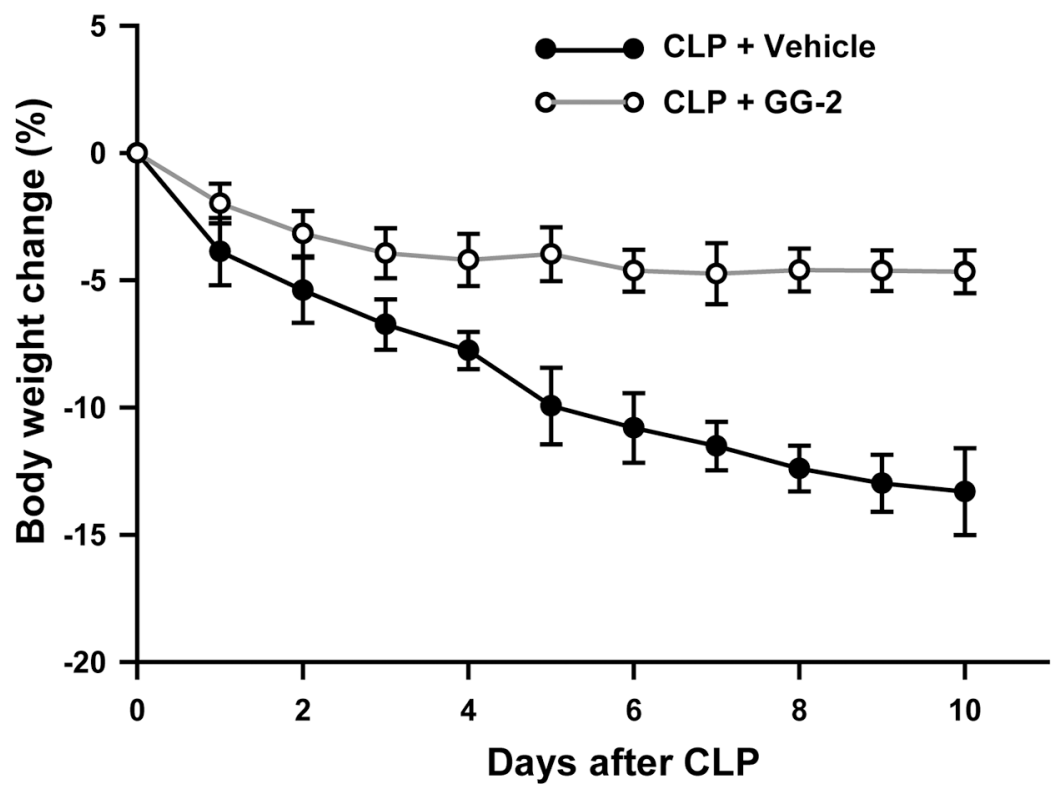

Figure 10. Effect of the combined treatment on survival and body weight change in aged septic rats. Rats were subjected to CLP with injection of vehicle (normal saline) or GG-2 (80 nmol/kg of ghrelin and $50 \mu \mathrm{g} / \mathrm{kg}$ of $\mathrm{GH}$ ) at $5 \mathrm{~h}$ after CLP. (A) Rats were monitored daily for $10 \mathrm{~d}$. The survival rate was analyzed by Kaplan-Meier survival analysis and compared by the log-rank test ( $n=14$ per group). ${ }^{*} P<0.05$ versus vehicle. (B) The daily body weight change of the surviving rats in a 10-d survival study. The percentage of body weight change is calculated by the difference from $\mathrm{d} 0$. Data are expressed as mean \pm SE were reported (42-45). The most common gastrointestinal side effect was gastric rumbles, which occurred in $2.3 \%$ of participants and was never severe enough to lead to ghrelin discontinuation (42).

Human GH is a Food and Drug Administration-approved drug for treating short stature in children with genetic disorders or chronic kidney failure and adults with short bowel syndrome, GH deficiency, or cachexia associated with AIDS. Some studies indicate that GH administration may improve the health of elderly people (46), although this claim is still disputable $(47,48)$. According to a meta-analysis from the published data, Liu et al. conclude that the benefit of GH therapy is very limited and the risk of adverse events is increased for healthy elderly individuals (49). Nonetheless, GH supplementation is widely advertised as an antiaging therapy. Furthermore, GH has also been studied in the treatment of critically ill patients. Administration of $\mathrm{GH}$ has been reported to be beneficial in postoperative patients and patients with burn or traumatic injury (50-52). On the other hand, Takala et al. report that treatment with recombinant $\mathrm{GH}$ is associated with increased morbidity and mortality in patients with prolonged critical illness (53); however, the high dose of GH used in that study may have contributed to insulin resistance, hyperglycemia and inhibition of immune function, which resulted in failure of the trial (53). Despite the controversy over the various uses of $\mathrm{GH}$, we demonstrate that in a low dose and in combination with ghrelin, GH can be a potential therapy for the treatment of critically ill elderly patients.

\section{CONCLUSION}

We have moved a step forward in translating a research concept into a potential therapeutic agent by demonstrating the efficacy of the combined treatment of human ghrelin and GH in aged septic animals. Both human ghrelin and $\mathrm{GH}$ are already available in drug format. Based on this study, we will further assess the optimal dose, drug-drug interactions, safety profile, pharmacokinetics and 
pharmacodynamics with coadministration of human ghrelin and GH. The ultimate goal is to bring the combined treatment to clinical trials for treating sepsis in the vulnerable geriatric population.

\section{ACKNOWLEDGMENTS}

This work was supported by the NIH grant R43AG046994 (to W-L Yang). The authors thank Alexandra C Bolognese and Nayaab Khan for critically reviewing the manuscript.

\section{DISCLOSURE}

$P$ Wang is an inventor of the United States Patent No. US 8,324,151 B2: “Treatment of sepsis and septic shock using ghrelin and growth hormone." TheraSource LLC holds the exclusive option to license the technology from the Feinstein Institute for Medical Research. P Wang is a cofounder of TheraSource LLC.

\section{REFERENCES}

1. Chang HJ, Lynm C, Glass RM. (2010) JAMA patient page. Sepsis. JAMA 304:1856.

2. Bosmann M, Ward PA. (2013) The inflammatory response in sepsis. Trends Immunol. 34:129-36.

3. Angus DC, et al. (2001) Epidemiology of severe sepsis in the United States: analysis of incidence, outcome, and associated costs of care. Crit. Care Med. 29:1303-10.

4. Martin GS, Mannino DM, Moss M. (2006) The effect of age on the development and outcome of adult sepsis. Crit. Care Med. 34:15-21.

5. Kojima M, et al. (1999) Ghrelin is a growth-hormone-releasing acylated peptide from stomach. Nature 402:656-60.

6. Takaya K, et al. (2000) Ghrelin strongly stimulates growth hormone release in humans. J. Clin. Endocrinol. Metab. 85:4908-11.

7. Arvat E, et al. (2001) Endocrine activities of ghrelin, a natural growth hormone secretagogue (GHS), in humans: comparison and interactions with hexarelin, a nonnatural peptidyl GHS, and GH-releasing hormone. J. Clin. Endocrinol. Metab. 86:1169-74

8. Date $Y$, et al. (2000) Ghrelin, a novel growth hormone-releasing acylated peptide, is synthesized in a distinct endocrine cell type in the gastrointestinal tracts of rats and humans. Endocrinology 141:4255-61.

9. Gnanapavan S, et al. (2002) The tissue distribution of the mRNA of ghrelin and subtypes of its receptor, GHS-R, in humans. J. Clin. Endocrinol. Metab. 87:2988.

10. Papotti M, et al. (2000) Growth hormone secretagogue binding sites in peripheral human tissues. J. Clin. Endocrinol. Metab. 85:3803-7.
11. Wang G, Lee HM, Englander E, Greeley GH, Jr (2002) Ghrelin —not just another stomach hormone. Regul. Pept. 105:75-81.

12. Kojima M, Kangawa K. (2005) Ghrelin: structure and function. Physiol. Rev. 85:495-522.

13. Wu R, et al. (2005) Ghrelin improves tissue perfusion in severe sepsis via downregulation of endothelin-1. Cardiovasc. Res. 68:318-26.

14. Wu R, et al. (2007) Ghrelin down-regulates proinflammatory cytokines in sepsis through activation of the vagus nerve. Ann. Surg. 245:480-6.

15. Wu R, et al. (2007) Ghrelin attenuates sepsis-induced acute lung injury and mortality in rats. Am. J. Respir. Crit. Care Med. 176:805-13.

16. Wu R, et al. (2012) Ghrelin maintains the cardiovascular stability in severe sepsis. J. Surg. Res. 178:370-7.

17. Li B, et al. (2015) Ghrelin protects alveolar macrophages against lipopolysaccharide-induced apoptosis through growth hormone secretagogue receptor 1a-dependent c-Jun $\mathrm{N}$-terminal kinase and Wnt/beta-catenin signaling and suppresses lung inflammation. Endocrinology 156:203-17.

18. Wei H, et al. (2015) Ghrelin inhibits proinflammatory responses and prevents cognitive impairment in septic rats. Crit. Care Med. 43:e143-50.

19. Wu R, et al. (2009) Ghrelin hyporesponsiveness contributes to age-related hyperinflammation in septic shock. Ann. Surg. 250:126-33.

20. Sherlock M, Toogood AA. (2007) Aging and the growth hormone/insulin like growth factor-I axis. Pituitary 10:189-203.

21. Nass R, Park J, Thorner MO. (2007) Growth hormone supplementation in the elderly. Endocrinol. Metab. Clin. North Am. 36:233-45.

22. Heemskerk VH, Daemen MA, Buurman WA. (1999) Insulin-like growth factor-1 (IGF-1) and growth hormone (GH) in immunity and inflammation. Cytokine Growth Factor Rev. 10:5-14.

23. Kolstad O, Jenssen TG, Ingebretsen OC, Vinnars E, Revhaug A. (2001) Combination of recombinant human growth hormone and glutamine-enriched total parenteral nutrition to surgical patients: effects on circulating amino acids. Clin. Nutr. 20:503-10.

24. Hattori N, et al. (2001) GH, GH receptor, GH secretagogue receptor, and ghrelin expression in human T cells, B cells, and neutrophils. J. Clin. Endocrinol. Metab. 86:4284-91.

25. Deitch EA. (1998) Animal models of sepsis and shock: a review and lessons learned. Shock 9:1-11.

26. Yang J, et al. (2009) Human adrenomedullin and its binding protein attenuate organ injury and reduce mortality after hepatic ischemia-reperfusion. Ann. Surg. 249:310-7.

27. Idrovo JP, Yang WL, Nicastro J, Coppa GF, Wang P. (2012) Stimulation of carnitine palmitoyltransferase 1 improves renal function and attenuates tissue damage after ischemia/reperfusion. J. Surg. Res. 177:157-64.

28. Andersen LW, et al. (2013) Etiology and therapeutic approach to elevated lactate levels. Mayo Clin. Proc. 88:1127-40.
29. Neumann B, et al. (1999) Mechanisms of acute inflammatory lung injury induced by abdominal sepsis. Int. Immunol. 11:217-27.

30. Nesseler N, et al. (2012) Clinical review: The liver in sepsis. Crit. Care 16:235.

31. Zarjou A, Agarwal A. (2011) Sepsis and acute kidney injury. J. Am. Soc. Nephrol. 22:999-1006.

32. Hotchkiss RS, Strasser A, McDunn JE, Swanson PE. (2009) Cell death. N. Engl. J. Med. 361:1570-83

33. Wang P, Zhou M, Rana MW, Ba ZF, Chaudry IH. (1992) Differential alterations in microvascular perfusion in various organs during early and late sepsis. Am. J. Physiol. 263:G38-43.

34. Kawashima T, Okuno H, Bito H. (2014) A new era for functional labeling of neurons: activity-dependent promoters have come of age. Front. Neural Circuits 8:37.

35. Pierrakos C, Vincent JL. (2010) Sepsis biomarkers: a review. Crit. Care 14:R15.

36. Suffredini AF, Munford RS. (2011) Novel therapies for septic shock over the past 4 decades. IAMA 306:194-9.

37. Jacob A, Wu R, Zhou M, Coppa GF, Wang P. (2010) Mechanism of the inhibitory effect of ghrelin in sepsis. Hepat. Med. 2:33-8.

38. Kobelt $\mathrm{P}$, et al. (2008) Peripheral injection of ghrelin induces Fos expression in the dorsomedial hypothalamic nucleus in rats. Brain Res. 1204:77-86.

39. Wu R, et al. (2007) Ghrelin inhibits sympathetic nervous activity in sepsis. Am. J. Physiol. Endocrinol. Metab. 293:E1697-702.

40. van der Lely AJ, Tschop M, Heiman ML, Ghigo E. (2004) Biological, physiological, pathophysiological, and pharmacological aspects of ghrelin. Endocr. Rev. 25:426-57.

41. Albarran-Zeckler RG, Smith RG. (2013) The ghrelin receptors (GHS-R1a and GHS-R1b). Endocr. Dev. 25:5-15.

42. Garin MC, Burns CM, Kaul S, Cappola AR. (2013) Clinical review: The human experience with ghrelin administration. J. Clin. Endocrinol. Metab. 98:1826-37.

43. Adachi S, et al. (2010) Effects of ghrelin administration after total gastrectomy: a prospective, randomized, placebo-controlled phase II study. Gastroenterology 138:1312-20.

44. Hiura Y, et al. (2012) Fall in plasma ghrelin concentrations after cisplatin-based chemotherapy in esophageal cancer patients. Int. J. Clin. Oncol. 17:316-23.

45. Lundholm K, et al. (2010) Effects by daily long term provision of ghrelin to unselected weight-losing cancer patients: a randomized double-blind study. Cancer 116:2044-52.

46. Rudman D, et al. (1990) Effects of human growth hormone in men over 60 years old. N. Engl. J. Med. 323:1-6.

47. Blackman MR, et al. (2002) Growth hormone and sex steroid administration in healthy aged women and men: a randomized controlled trial. JAMA 288:2282-92. 
48. Lange KH, et al. (2002) Acute growth hormone administration causes exaggerated increases in plasma lactate and glycerol during moderate to high intensity bicycling in trained young men. J. Clin. Endocrinol. Metab. 87:4966-75.

49. Liu H, et al. (2007) Systematic review: the safety and efficacy of growth hormone in the healthy elderly. Ann. Intern. Med. 146:104-15.

50. Duska F, et al. (2008) Frequent intravenous pulses of growth hormone together with glutamine supplementation in prolonged critical illness after multiple trauma: effects on nitrogen balance, insulin resistance, and substrate oxidation. Crit. Care Med. 36:1707-13.

51. Jeschke MG, et al. (2008) Combination of recombinant human growth hormone and propranolol decreases hypermetabolism and inflammation in severely burned children. Pediatr. Crit. Care Med. 9:209-16.

52. Branski LK, et al. (2009) Randomized controlled trial to determine the efficacy of long-term growth hormone treatment in severely burned children. Ann. Surg. 250:514-23.

53. Takala J, et al. (1999) Increased mortality associated with growth hormone treatment in critically ill adults. N. Engl. J. Med. 341:785-92.

Cite this article as: Yang W-L, et al. (2016) Combined administration of human ghrelin and human growth hormone attenuates organ injury and improves survival in aged septic rats. Mol. Med. 22:124-35. 